\title{
Cephalometric Evaluation of Craniofacial Morphology in Pediatric Patients With Fully Diagnosed OSA With Distinct Sagittal Skeletal Malocclusions
}

\author{
Simona Pisacane, DDS, MS ${ }^{1}$; Marco Carotenuto, DDS, MS, PhD²; Fabrizia d'Apuzzo, DDS, MS, PhD'; Maddalena Vitale, DDS, MS, \\ $\mathrm{PhD}^{1}$; Vincenzo Grassia, DDS, MS, PhD ${ }^{1}$; Carlos Flores-Mir, DDS, BSc, MSc, DSc ${ }^{3}$; Letizia Perillo, DDS, MS, $\mathrm{PhD}^{1 *}$
}

\footnotetext{
${ }^{1}$ Multidisciplinary Department of Medical-Surgical and Dental Specialties, University of Campania Luigi Vanvitelli, Naples, Italy; ${ }^{2}$ Department of Mental and Physical Health, University of Campania Luigi Vanvitelli, Naples, Italy ; ${ }^{3}$ Department of Orthodontics, University of Alberta,
} Edmonton, Canada

\begin{abstract}
Study Objectives: To establish whether craniofacial and nasopharyngeal morphology, assessed through lateral cephalometry, in children properly diagnosed with obstructive sleep apnea (OSA) differed from that of non-likely OSA control children stratified based on sagittal malocclusion and to evaluate if there is any association with apneahypopnea index (AHI) severity.

Materials and Methods: Various cephalometric measurements were compared between 22 children (mean age 8.8) with nocturnal polysomnography (nPSG) diagnosed OSA that had already adeno-tonsillectomy and a control group of 20 nonlikely OSA children (mean age 9.2) based on a negative pediatric sleep questionnaire (PSQ) results matched for age, sex and sagittal malocclusion.

Results: Statistically significant increases in Go-Me and $\mathrm{Ba}^{\wedge} \mathrm{SN}$ dimensions were observed among OSA children when higher AHI values (4.5 and $4 \mathrm{~mm}$ ), whereas ANSPNS dimension was significantly increased in the Class II sample according to OSA severity (3.5 $\mathrm{mm})$. No significant differences were identified for any variables among Class III based on OSA severity. In comparison to controls, in Class II both the angle between palatal plane and anterior cranial base and the angle of the flexure of cranial base were significantly reduced in OSA children $(0.36$ and $2.3 \mathrm{~mm})$. In addition, an increased thickness of the upper adenoid profile and a reduced dimension of upper pharynx were observed (3.2 and $2.1 \mathrm{~mm}$ ). In Class III a shorter bony nasopharynx was statistically significant (3.2 mm).

Conclusions: The OSA sample showed some distinct craniofacial features compared to a non-likely OSA group. These differences were not consistently located when sagittal malocclusion was considered.
\end{abstract}

Keywords: obstructive sleep apnea, nasopharynx, craniofacial features, malocclusions

Citation: Pisacane S, Carotenuto M, d'Apuzzo F, Vitale M, Grassia V, Flores-Mir C, Perillo L. Cephalometric evaluation of craniofacial morphology in pediatric patients with fully diagnosed OSA with distinct sagittal skeletal malocclusions. J Dent Sleep Med. 2019;6(4)

\section{INTRODUCTION}

Obstructive sleep apnea (OSA) is a form of sleep-disordered breathing (SDB). Patients with OSA experience repeated episodes of partial or complete airway obstruction during sleep. ${ }^{1}$ The prevalence of OSA in children ranges from $1 \%$ to $4 \% .^{2}$ The pathophysiology of OSA is frequently associated with an increased upper airway resistance. This can affect the pulmonary ventilation, oxygenation, and sleep quality. ${ }^{3}$ In a smaller number of OSA cases sleep breathing issues are linked to a central nervous system origin. ${ }^{4}$

Although the most common cause of pediatric OSA is adenotonsillar hypertrophy, other factors such as unfavorable craniofacial skeletal morphology and growth patterns, nasal anatomic abnormalities, chronic sinusitis or allergic rhinitis, obesity, waist and neck circumference, and neuromuscular disorders have to be considered. ${ }^{5}$

OSA is often associated with various symptoms such as loud and abnormal snoring or breathing, agitated sleep, frequent arousals, unusual sleeping positions, sweating during sleep, and nocturnal enuresis. ${ }^{6}$ All of these symptoms could be associated with excessive daytime fatigue, morning headaches, impaired intellectual function and attention (school performance), mood disturbance, aggressive behavior, and hyperactivity. ${ }^{7}$

The reference standard to diagnose OSA is nocturnal polysomnography (nPSG), which allows clinicians to evaluate the number of obstructive apneas and hypopneas per hour of sleep using the apnea-hypopnea index (AHI), and also to assess other sleep-related variables. ${ }^{8}$ However, nPSG is expensive, time-consuming, and frequently inaccessible; thus, sleep breathing performance questionnaires have been proposed alternatively to at least suggest the presence of OSA in children. Among all the available questionnaires, the Pediatric Sleep Questionnaire (PSQ) is the one of choice. ${ }^{9}$ Its negative predictive value is almost perfect $(99.9 \%)$. Previous cephalometric investigations on children with OSA have been synthesized in two systematic reviews with meta-analyses. ${ }^{6,10}$ Decreased mandibular prominence, bimaxillary retrusion with reduced lengths, increased mandibular plane angle, and low hyoid position were all significantly associated with OSA. However, only a limited number of cephalometric variables were reported in the included studies and almost always focused on late deciduous or early mixed dentition cases ( 4 to 8 years of 
age). The age of 7 to 14 years (mid- to late mixed dentition) is usually when orthodontists do complete an initial orthodontic screening. Therefore, information from a later age, to be contrasted with previously younger reported samples, may allow identifying trends in how those cephalometric variables may have changed in older children populations if left untreated. Furthermore, in previous investigations patients and control patients were not differentiated based on a clearly defined craniofacial morphology. Hence, the objective of this study was to establish whether craniofacial and upper airways morphology in children aged 7 to 14 years suffering from OSA differed in any respect from that of non-obstructed control patients when matched based on sagittal malocclusion classification and subsequently to identify any correlation of the cephalometric variables with AHI severity.

\section{MATERIAL AND METHODS}

The study protocol was approved by the Ethics Committee of the University of Campania Luigi Vanvitelli. Proper informed consent was obtained from the parents/guardian of each participant. The sample was selected from consecutive children referred to the Orthodontic Division of the University of Campania Luigi Vanvitelli, Naples, Italy, from 2015 to 2018.

Selection criteria used for the study were: (1) age range 7 to 14 years; (2) no previous orthodontic treatment; (3) previous adenotonsillectomy; (4) absence of clinically noticeable craniofacial syndromes; (5) absence of obesity (BMI $\leq 95$ percentile). ${ }^{11}$ A validated questionnaire (PSQ) was used for screening patients with suspected OSA. The parents of the selected children filled out this questionnaire regarding nocturnal and daytime potential obstructive sleep breathing signs and symptoms. All children with a positive questionnaire for suspected OSA were selected for the study and the definitive diagnosis was obtained through nPSG. All children with a negative questionnaire for OSA comprised the control group. As explained previously, a negative PSQ test almost always implies absence of OSA. Straining the PSG resources for cases unlikely to have OSA is questionable. A convenience sample of at least 20 subjects in each group with and without OSA was sought based on available records.

The PSQ questionnaire was used, including 22 symptom items about snoring frequency, loud snoring, observed apneas, difficulty breathing during sleep, daytime sleepiness, inattentive or hyperactive behavior, and other pediatric OSA features. A cutoff value of 0.33 was considered effective in suggesting pediatric OSAS. ${ }^{9}$

The OSA was definitively diagnosed by a sleep medicine specialist at the Department of Mental and Physical Health and Preventive Medicine, Child and adolescent Neuropsychiatry of the University of Campania Luigi Vanvitelli, Naples, Italy, using a standardized nPSG, clinic, and other diagnostic criteria to evaluate the incidence of breathing abnormalities and oxygen saturation. Oxygen saturations were computed to determine the following measures: mean saturation of oxygen $\left(\mathrm{SpO}_{2}\right)$ during sleep time; $\mathrm{SpO}_{2}$ nadir; and $\mathrm{SpO}_{2}$ desaturation indices during total sleep time, rapid eye movement, and non-rapid eye movement. An average number of oxygen desaturation events per hour during sleep was also evaluated. The severity of OSA was expressed using the AHI, which was calculated as the sum of obstructive and mixed apneas and hypopneas per hour of sleep during PSG monitoring. AHI was considered abnormal in these children when the value was greater than 1 , which was used as the criterion for OSA. ${ }^{8}$ On the basis of AHI, children in whom OSA was diagnosed were categorized into an $\mathrm{AHI}<5$ events/h group or $\mathrm{AHI}>5$ events $/ \mathrm{h}$ group to assess OSA severity dichotomously. An AHI $>5$ events/h is considered moderate to severe in children. ${ }^{12}$

The skeletal malocclusions were identified as class II when children had an ANB angle of $+5^{\circ}$ or more and a Wits value $>2 \mathrm{~mm}$, and as class III with an ANB angle of $0^{\circ}$ or less and a Wits value $\leq 2 \mathrm{~mm}$. Lateral radiographic examinations were performed for each subject in both groups and analyzed by using a standardized protocol with an $8 \%$ magnification factor. The cephalometric analysis included common linear and angular measurements along with specific variables to evaluate the nasopharyngeal and oropharyngeal airway dimensions ${ }^{13,14}$

(Figure 1) (Appendix I and II).

Figure 1. Representation of cephalometric skeletal and soft-tissue variables.

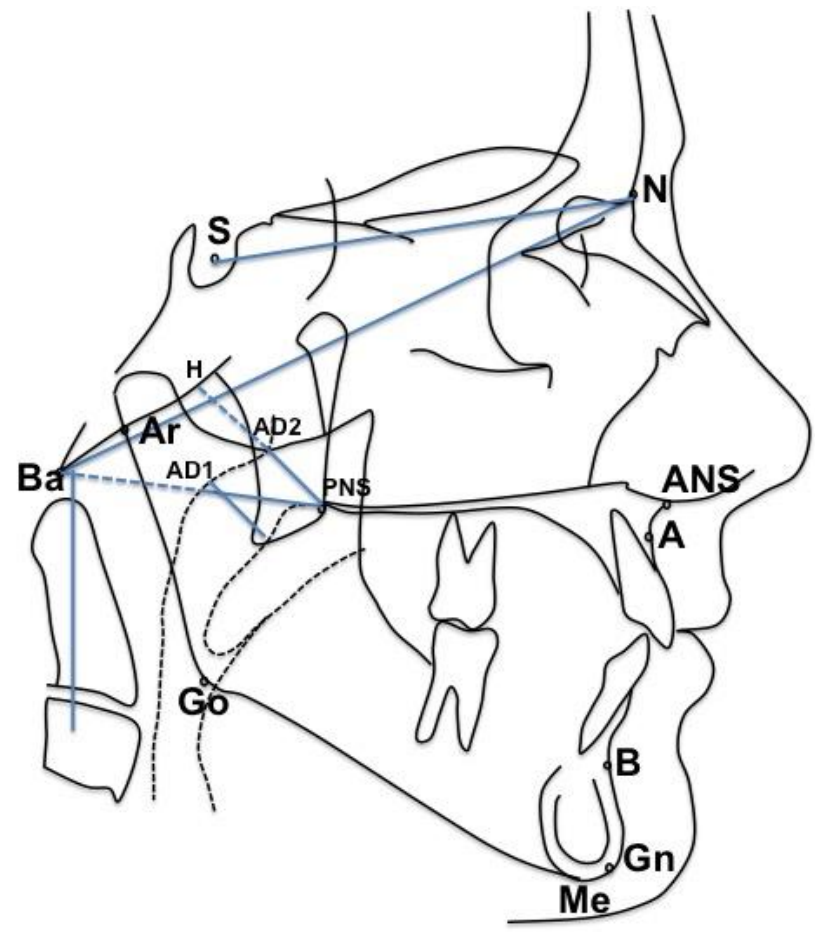




\section{Statistical Analysis}

All lateral cephalograms were hand-traced by the same operator. Ten radiographs chosen at random were retraced and measured again by two different operators with the same expertise 4 weeks apart in order to calculate the intraobserver and interobserver errors of method, which was determined by intraclass and interclass correlation coefficients using an absolute agreement definition for each variable.

Data are presented as mean and standard deviation. Unpaired $t$ tests, assuming equality of variance, were used to compare all cephalometric variables between patients with OSA and control patients. Correlation coefficients were determined by Pearson chi-square test for the association between the cephalometric variables and degree of AHI score severity. Fisher exact test was used to compare age and sex difference in the groups. The partial correlation analysis was used to evaluate the influence of age on the relationship between $\mathrm{AHI}$ and skeletal and upper airways variables. A value of $P<0.05$ was considered significant. Statistical analyses were performed with a statistical package (SPSS software, IBM, Armonk, New York, USA).

\section{RESULTS}

The OSA group included 22 children (13 males, 9 females; mean age $8.8 \pm 1.8$ years). The control group consisted of 20 subjects without OSA (10 males, 10 females; mean age $9.2 \pm 1.7$ years) matched for age, sex, and malocclusion classification.

For the lateral cephalometric measurements, interreliability was intraclass correlation coefficient $=0.99(95 \%$ confidence interval 0.984, 0.996).

Each group was further subdivided based on skeletal profile (class II and III malocclusion). In the OSA group, 11 children ( 8 males, 3 females; mean age $8.5 \pm 2.0$ years) had a class II malocclusion and 11 children ( 5 males, 6 females; mean age $9.1 \pm 1.6$ years) a class III malocclusion. In the control group, 10 children ( 5 males, 5 females; mean age $8.8 \pm 1.7$ years) had a class II malocclusion and 10 children ( 5 males, 5 females; mean age $9.3 \pm 2.0$ years) a class III malocclusion.

\section{AHI-Based Results}

Sleep-based results revealed mean AHI of $6.7 \pm 3.7$ events per hour, mean oxygen desaturation index $1.76 \pm 1.79 \%$, mean $\mathrm{SaO}_{2} 97.4 \pm 1.0 \%$, mean nadir $\mathrm{O}_{2}$ $91.4 \pm 5.4 \%$ and mean $\mathrm{O}_{2}$ desaturation $3.7 \pm 1.4 \%$. In the OSA group 13 children (60.7\%) had an AHI $>5$ events/h and 9 children (39.3\%) had an AHI $<5$ events/h. In the subgroup of $\mathrm{AHI}>5$ events/h there were 5 children with class II malocclusion and 8 children with class III malocclusion, whereas in the $\mathrm{AHI}<5$ events/h group there were 6 children with class II malocclusion and 3 with class III malocclusion.

A statistically significant difference was observed only for Go-Me and $\mathrm{Ba}^{\wedge} \mathrm{SN}$ dimensions when children with OSA were grouped for AHI $>5$ events/h or $<5$ events $/ \mathrm{h}(P$ $=0.029$ and $P=0.026$, respectively). For the Go-Me and $\mathrm{Ba}^{\wedge} \mathrm{SN}$ dimensions the smaller values were observed in children with AHI $<5$ events/h (around $4.5 \mathrm{~mm}$ and $4^{\circ}$, respectively). Only ANS-PNS was significantly increased in the class II malocclusion sample according to OSA severity (around $3.5 \mathrm{~mm} ; P=0.03$ ). (Appendix IV) Finally, there was no significant difference for any variables among class III malocclusion based on OSA severity (Appendix V).

\section{Skeletal Results}

A significant decrease in the angle between palatal plane and anterior cranial base $\left(\mathrm{PP}^{\wedge} \mathrm{SN}\right)$ was evident in children with OSA compared to the control patients (7.55 \pm 2.04 vs. $9.80 \pm 2.91 ; P=0.006$ ) (Table 1 ). However, this reduction was statistically significant only in children with OSA with class II malocclusion compared to the class II control group, but not in class III malocclusions (Tables 2 and 3). Although a reduction of $\mathrm{PP}^{\wedge} \mathrm{SN}$ was observed in both OSA class II and III malocclusions, the difference was not significant $(7.18 \pm 1.72$ vs. $7.54 \pm 2.46 ; P>0.05)$. The angle of the flexure of cranial base $\left(\mathrm{Ba}^{\wedge} \mathrm{SN}\right)$ was reduced in children with OSA when compared to control patients $(129.68 \pm 4.21$ vs. $132.0 \pm 3.46 ; p=0.05)$. (Table 1$)$ This reduction was only present in class II malocclusion (Table 2). No statistically significant difference was found when mean values were compared in OSA class II and III malocclusions ( $129.72 \pm 2.57$ vs. $130.45 \pm 5.44 ; P>0.05)$. No significant differences were observed for other skeletal variables between children with OSA and the control group.

\section{Upper Airway Results}

Total lower sagittal depth of the bony nasopharynx (PNS-Ba) was significantly reduced in the OSA group when compared to the control group $(40.32 \pm 2.81$ vs. $42.33 \pm 3.38 ; P=0.043$ ) (Table 1). This variable decreased only in class III malocclusion compared to controls (40.36 \pm 2.76 vs. $43.55 \pm 3.18 ; p=0.024)$. (Tables 2 and 3 ) No difference was found when mean values were compared in OSA class II and III malocclusions $(40.36 \pm 2.97$ vs. $40.36 \pm 2.76 ; P>0.05)$. The upper adenoid thickness $(\mathrm{AD} 2 \mathrm{H})$ was increased in the OSA group when compared to the control group $(17.41 \pm 3.59$ vs. $14.35 \pm 2.92 ; P=0.005)$ (Table 1). The increase was evident only in OSA class II malocclusion compared to the control group (Tables 2 and $3)$. No significant difference was noted between OSA class II and III malocclusions (16.54 \pm 3.77 vs. $17.81 \pm 3.7 ; P$ $>0.05$ ). The minimal distance between the upper soft palate and the nearest point on the posterior pharynx wall 
Table 1. Comparison between OSA group and controls.

\begin{tabular}{llll}
\hline Variables & $\begin{array}{l}\text { OSA group } \\
\text { N=22 }\end{array}$ & $\begin{array}{l}\text { Control group } \\
\text { N=22 }\end{array}$ & $\begin{array}{l}\boldsymbol{P} \text { - } \\
\text { value }\end{array}$ \\
\hline Skeletal & & & \\
\hline Age & $8.87 \pm 1.81$ & $9.2 \pm 1.7$ & $\mathrm{NS}$ \\
S-N & $62.18 \pm 3.12$ & $62.45 \pm 4.65$ & $\mathrm{NS}$ \\
ANS-PNS & $42.36 \pm 3.23$ & $43.50 \pm 3.48$ & $\mathrm{NS}$ \\
Go-Me & $59.98 \pm 5.03$ & $61.58 \pm 4.38$ & $\mathrm{NS}$ \\
SNA & $80.02 \pm 3.38$ & $79.90 \pm 3.38$ & $\mathrm{NS}$ \\
SNB & $76.14 \pm 4.0$ & $76.25 \pm 3.32$ & $\mathrm{NS}$ \\
ANB & $3.88 \pm 2.76$ & $3.65 \pm 2.73$ & $\mathrm{NS}$ \\
WITS & $0.39 \pm 4.39$ & $0.23 \pm 3.79$ & $\mathrm{NS}$ \\
A-NPerp & $0.79 \pm 2.69$ & $0.42 \pm 2.83$ & $\mathrm{NS}$ \\
$\mathrm{B}-\mathrm{NPerp}$ & $-4.25 \pm 5.83$ & $-4.60 \pm 4.38$ & $\mathrm{NS}$ \\
SN^PHF & $10.64 \pm 2.58$ & $11.25 \pm 2.77$ & $\mathrm{NS}$ \\
FMA & $23.23 \pm 4.38$ & $24.85 \pm 4.69$ & $\mathrm{NS}$ \\
SN^GoMe & $33.82 \pm 4.32$ & $36.10 \pm 6.14$ & $\mathrm{NS}$ \\
PP^SN & $7.55 \pm 2.04$ & $9.80 \pm 2.91$ & 0.006 \\
PP^GoMe & $26.27 \pm 4.77$ & $26.35 \pm 6.03$ & $\mathrm{NS}$ \\
ArGo^Me & $125.82 \pm 5.42$ & $126.50 \pm 6.08$ & $\mathrm{NS}$ \\
Ba^SN & $129.68 \pm 4.21$ & $132.0 \pm 3.46$ & 0.05 \\
S-Go/N-Me & $63.09 \pm 4.29$ & $61.35 \pm 4.79$ & $\mathrm{NS}$ \\
Ar-Go/Ans-Me & $71.15 \pm 7.37$ & $68.60 \pm 8.70$ & $\mathrm{~N}$ \\
\hline Dental & & & \\
\hline U1-PP & $114.95 \pm 6.91$ & $113.60 \pm 8.47$ & $\mathrm{NS}$ \\
IMPA & $93.23 \pm 5.73$ & $92.90 \pm 7.84$ & $\mathrm{NS}$ \\
\hline Upper Airway & & & \\
\hline PNS-AD1 & $18.32 \pm 5.19$ & $20.83 \pm 3.71$ & $\mathrm{NS}$ \\
AD1-Ba & $21.95 \pm 3.76$ & $21.50 \pm 4.54$ & $\mathrm{NS}$ \\
PNS-Ba & $40.32 \pm 2.81$ & $42.33 \pm 3.38$ & 0.043 \\
PNS-AD2 & $12.16 \pm 2.99$ & $13.60 \pm 2.54$ & NS \\
AD2H & $17.41 \pm 3.59$ & $14.35 \pm 2.92$ & 0.005 \\
PNS-H & $29.48 \pm 2.88$ & $27.95 \pm 3.42$ & NS \\
McNamara & & & \\
upper pharynx & $9.91 \pm 2.65$ & $11.93 \pm 2.34$ & 0.013 \\
McNamara & & & \\
middle pharynx & $9.45 \pm 2.26$ & $9.40 \pm 1.98$ & NS \\
McNamara & & & \\
lower pharynx & $9.55 \pm 2.50$ & $8.70 \pm 2.31$ & NS \\
\hline & & & \\
\hline
\end{tabular}

(McNamara upper pharynx dimension) was significantly reduced in the OSA group when compared to that of the control group $(9.91 \pm 2.65$ vs. $11.93 \pm 2.34 ; P=0.01)$ (Table $1)$. This variable decreased only in class II when compared to that of the control group $(9.27 \pm 2.83$ vs. $11.40 \pm 1.77 ; P=$ 0.05 ) (Table 2). No difference was found when mean values were compared in OSA class II and III malocclusions $(9.27 \pm 2.83$ vs. $10.72 \pm 2.45 ; P>0.05)$.

\section{Correlation Analysis}

Because correlation with AHI index may be caused by the common dependence on age, it is important to eliminate this confounding factor. Skeletal and upper airway cephalometric measurements were correlated with age in the OSA group. Some upper airway variables (PNS-AD1,
Table 2. Comparison between OSA Class II group and controls.

\begin{tabular}{llll}
\hline Variables & $\begin{array}{l}\text { OSA class II } \\
\text { group }\end{array}$ & $\begin{array}{l}\text { Control class } \\
\text { II group }\end{array}$ & P-value \\
N=11 & & & \\
\hline Skeletal & & & \\
\hline Age & $8.56 \pm 2.01$ & $9.26 \pm 1.47$ & NS \\
S-N & $62.36 \pm 3.47$ & $60.80 \pm 4.31$ & NS \\
ANS-PNS & $43.27 \pm 2.90$ & $44.20 \pm 3.08$ & NS \\
Go-Me & $59.0 \pm 5.72$ & $59.40 \pm 2.45$ & NS \\
SNA & $80.27 \pm 3.13$ & $81.0 \pm 2.66$ & NS \\
SNB & $74.27 \pm 3.60$ & $75.0 \pm 2.94$ & NS \\
ANB & $6.6 \pm 1.73$ & $6.0 \pm 1.05$ & NS \\
WITS & $3.90 \pm 2.66$ & $3.30 \pm 1.49$ & NS \\
A-NPerp & $0.63 \pm 2.94$ & $1.10 \pm 2.33$ & NS \\
B-NPerp & $-7.54 \pm 4.88$ & $-6.60 \pm 3.74$ & NS \\
SN^PHF & $10.18 \pm 1.32$ & $10.90 \pm 2.76$ & NS \\
FMA & $24.36 \pm 5.53$ & $21.00 \pm 4.98$ & NS \\
SN^GoMe & $34.45 \pm 5.39$ & $43.90 \pm 6.78$ & NS \\
PP^SN & $7.18 \pm 1.72$ & $10.0 \pm 2.66$ & 0.009 \\
PP^GoMe & $27.27 \pm 6.14$ & $25.0 \pm 6.56$ & NS \\
ArGo^Me & $125.54 \pm 5.5$ & $124.80 \pm 7.31$ & NS \\
Ba^SN & $129.72 \pm 2.57$ & $132.20 \pm 2.57$ & 0.04 \\
S-Go/N-Me & $63.18 \pm 5.43$ & $61.90 \pm 5.80$ & NS \\
Ar-Go/Ans- & $69.0 \pm 8.37$ & $69.70 \pm 8.51$ & NS \\
Me & & & \\
& & & \\
\hline Dental & & & \\
\hline U1-PP & $115.18 \pm 5.23$ & $112.30 \pm 10.31$ & NS \\
IMPA & $98.18 \pm 3.97$ & $96.70 \pm 6.51$ & NS \\
& & & \\
\hline Upper Airway & & & \\
\hline PNS-AD1 & $19.09 \pm 4.98$ & $20.90 \pm 2.76$ & NS \\
AD1-Ba & $21.27 \pm 3.79$ & $20.20 \pm 3.19$ & NS \\
PNS-Ba & $40.36 \pm 2.97$ & $41.10 \pm 3.28$ & NS \\
PNS-AD2 & $12.45 \pm 3.32$ & $14.20 \pm 2.69$ & NS \\
AD2H & $16.54 \pm 3.77$ & $12.50 \pm 1.77$ & 0.006 \\
PNS-H & $20.18 \pm 2.56$ & $26.70 \pm 3.46$ & NS \\
McNamara & $9.27 \pm 2.83$ & $11.40 \pm 1.77$ & 0.05 \\
upper pharynx & & & \\
McNamara & $9.90 \pm 1.86$ & $9.30 \pm 2.16$ & NS \\
middle & & & \\
pharynx & & & \\
McNamara & $10.09 \pm 2.70$ & $8.40 \pm 2.22$ & NS \\
lower pharynx & & & \\
\hline & & & \\
\hline
\end{tabular}

PNS-Ba, PNS-AD2 and AD2H) resulted in correlation with age (around $\mathrm{r}=0.5$; all $P<0.03$ ). In addition, a low but significant positive correlation was observed between AHI and age $(\mathrm{r}=0.38 ; p=0.04)$. AHI value was not strongly correlated with any skeletal and upper airway variables in the OSA group (Appendix VI). There was also no correlation between AHI in children with class II and III malocclusion for both skeletal and upper airways measurements. 
Table 3. Comparison between OSA Class III group and controls.

\begin{tabular}{|c|c|c|c|}
\hline Variables & $\begin{array}{c}\text { OSA Class III } \\
\text { group } \\
\mathbf{N}=11\end{array}$ & $\begin{array}{l}\text { Control Class } \\
\text { III group } \\
\mathbf{N = 1 0}\end{array}$ & $\begin{array}{c}P \text { - } \\
\text { value }\end{array}$ \\
\hline \multicolumn{4}{|l|}{ Skeletal } \\
\hline Age & $9.08 \pm 1.74$ & $9.3 \pm 2.09$ & NS \\
\hline $\mathrm{S}-\mathrm{N}$ & $62.36 \pm 2.87$ & $64.10 \pm 4.58$ & NS \\
\hline ANS-PNS & $41.54 \pm 3.41$ & $42.80 \pm 3.88$ & NS \\
\hline Go-Me & $60.77 \pm 4.45$ & $63.75 \pm 4.90$ & NS \\
\hline SNA & $79.04 \pm 3.63$ & $78.80 \pm 3.79$ & NS \\
\hline SNB & $77.18 \pm 3.86$ & $77.50 \pm 3.34$ & NS \\
\hline ANB & $1.86 \pm 1.89$ & $1.30 \pm 1.56$ & NS \\
\hline WITS & $-2.86 \pm 2.66$ & $-2.85 \pm 2.68$ & NS \\
\hline A-NPerp & $0.59 \pm 2.67$ & $-0.25 \pm 3.24$ & NS \\
\hline B-NPerp & $-1.68 \pm 5.28$ & $-2.60 \pm 4.19$ & NS \\
\hline $\mathrm{SN}^{\wedge} \mathrm{PHF}$ & $11.18 \pm 2.89$ & $11.60 \pm 2.87$ & NS \\
\hline FMA & $22.63 \pm 2.97$ & $25.70 \pm 4.47$ & NS \\
\hline $\mathrm{SN}^{\wedge} \mathrm{GoMe}$ & $33.81 \pm 3.28$ & $37.30 \pm 5.51$ & NS \\
\hline $\mathrm{PP}^{\wedge} \mathrm{SN}$ & $7.54 \pm 2.46$ & $9.60 \pm 3.27$ & NS \\
\hline $\mathrm{PP}^{\wedge} \mathrm{GoMe}$ & $26.27 \pm 3.40$ & $27.70 \pm 5.45$ & NS \\
\hline $\mathrm{ArGo}^{\wedge} \mathrm{Me}$ & $126.27 \pm 5.58$ & $128.20 \pm 4.26$ & NS \\
\hline $\mathrm{Ba}^{\wedge} \mathrm{SN}$ & $130.45 \pm 5.44$ & $131.80 \pm 4.31$ & NS \\
\hline S-Go/N-Me & $61.90 \pm 3.20$ & $60.80 \pm 3.76$ & NS \\
\hline Ar-Go/Ans-Me & $71.50 \pm 6.26$ & $67.50 \pm 9.21$ & NS \\
\hline \multicolumn{4}{|l|}{ Dental } \\
\hline U1-PP & $113.54 \pm 7.68$ & $114.90 \pm 6.43$ & NS \\
\hline IMPA & $89.90 \pm 5.48$ & $89.10 \pm 7.44$ & NS \\
\hline \multicolumn{4}{|l|}{ Upper Airway } \\
\hline PNS-AD1 & $17.90 \pm 5.68$ & $20.75 \pm 4.63$ & NS \\
\hline $\mathrm{AD} 1-\mathrm{Ba}$ & $22.36 \pm 4.0$ & $22.8 \pm 5.45$ & NS \\
\hline PNS-Ba & $40.36 \pm 2.76$ & $43.55 \pm 3.18$ & 0.024 \\
\hline PNS-AD2 & $12.13 \pm 2.81$ & $13 \pm 2.35$ & NS \\
\hline $\mathrm{AD} 2 \mathrm{H}$ & $17.81 \pm 3.7$ & $16.20 \pm 2.69$ & NS \\
\hline PNS-H & $29.95 \pm 2.93$ & $29.2 \pm 3.04$ & NS \\
\hline $\begin{array}{l}\text { McNamara } \\
\text { upper pharynx }\end{array}$ & $10.72 \pm 2.45$ & $12.46 \pm 2.79$ & NS \\
\hline $\begin{array}{l}\text { McNamara } \\
\text { middle } \\
\text { pharynx }\end{array}$ & $9.18 \pm 2.60$ & $9.50 \pm 1.90$ & NS \\
\hline $\begin{array}{l}\text { McNamara } \\
\text { lower pharynx }\end{array}$ & $9.45 \pm 2.33$ & $9.0 \pm 2.49$ & NS \\
\hline
\end{tabular}

\section{DISCUSSION}

The results suggest that differences in prevalence for some cephalometric variables existed between children with and without OSA. Those altered features are not necessarily similar to those reported in previous systematic reviews. ${ }^{6,10}$

In contrast to other studies, ${ }^{15}$ the current study did not suggest a significant difference between many cephalometric variables in patients with and without OSA. It has been reported ${ }^{10}$ that $\mathrm{SNB}$ and $\mathrm{ANB}$ appeared to showcase that mandibular retrusion was associated with OSA in pediatric patients. However, the reliability of these variables as indicators of sagittal maxillary and mandibular position is directly affected by vertical SN pitch and horizontal SN length. ${ }^{16}$ Moreover, a short SN measure for anterior cranial base length has also been reported in children with OSA. ${ }^{17}$ Consequently, a short cranial base could incorrectly show normal ANB, SNA, and SNB values despite the presence of mandibular retrusion. ${ }^{10}$ For this reasons, in addition the Wits index was applied to have further agreement of sagittal skeletal discrepancy in case that ANB measurements were ineffective in assessing the real intermaxillary relationships. ${ }^{18}$ Flores-Mir et al. ${ }^{10}$ stated that most of selected studies had various methodologic deficiencies and lack of appropriate control group. In this study, the two groups of children were matched based on skeletal craniofacial characteristics and the only difference was the presence/absence of OSA. It seemed that making an overlap between the two groups of patients regarding their basic skeletal characteristics could be methodologically more correct, avoiding differences in skeletal variables only because of an erroneous sampling of the control group. Therefore, the absence of statistically significant differences between sagittal skeletal variables in the groups of children was expected and related to comparable skeletal changes already present in basal conditions and secondary to malocclusion. The lack of vertical skeletal differences may indicate that, at least for some skeletal variables, the presence of OSA may not further change the skeletal morphology in patients with class II and III malocclusions. Moreover, the absence of any meaningful correlation with OSA severity may indicate that craniofacial morphology may not represent a clear pathway in the development of OSA. Hence, clinicians should be careful in only considering the OSA potential in children with the "adenoidal face" because this may still present a significant degree of OSA.

The identified correlation between $\mathrm{AHI}$ and age should be carefully considered. It has been previously reported that the severity of OSA tends to increase over time. Children with untreated OSA can exhibit serious morbidity in physical growth and development. ${ }^{19}$

In regard to the maxilla inclination, in this study it was significantly decreased in children with OSA, particularly those with class II malocclusion, indicating that the maxilla was inclined upward, whereas the anterior cranial base inclination appeared normal. Similar results were reported by Zettergren-Wijk et al. ${ }^{19}$ in children with OSA, speculating that the reduction of this angle may be influenced by the sleep breathing problem. No significant correlations between maxilla inclination and AHI severity were found.

An interesting observation was that children with OSA trended toward a less obtuse cranial base flexure angle, mainly in class II malocclusion. Steinberg et al. ${ }^{20} \mathrm{ob}-$ served that adults with OSA "tended to have a more acute cranial base flexure angle compared to patients without" OSA regardless of malocclusions. In particular, "patients 
with class III tended to have a more acute cranial base flexure angle than those with class I or II". In the children with OSA in the current study, this reduction was evident in both class II and III malocclusions but with a significantly lower value in OSA Class II. Özdemir et al. ${ }^{21}$ found a statistically significant negative correlation between skull-base angle and AHI score and found that in patients with severe obstruction the reduction of this angle was caused by a reduction of the bony limits of nasopharyngeal space. In addition, they stated that excessive cranial-base flexure could play a role in the development of OSA. No significant correlation between skull-base angle and AHI score was found.

Regarding the upper airway profile, children with OSA have a reduced anteroposterior airway width located at the level of the lower bony nasopharynx, superiorly at the level of the upper adenoidal mass and in the upper pharynx. Although the reduction of the upper airway width was evident in children with OSA, it is important to note that no difference was found between children with and without OSA in class II and III malocclusions. ${ }^{22,23}$ As a consequence, it can be presumed that the upper airway width may be reduced regardless of the sagittal malocclusion, appearing to be more influenced by changes in soft palate and adenoidal mass. Another hypothesis could be that in both class II and III malocclusion the maxilla is size deficient. Furthermore, we failed to show any correlation between upper airway width and AHI severity. Our results are supported by the observation of de Freitas et al., ${ }^{17}$ who noted no association between class I or II malocclusion and pharyngeal airway dimensions, inferring that malocclusion type does not influence pharyngeal airways width. Alves et al., ${ }^{24}$ in a three-dimensional cephalometric study from CT scans in adults with normal nasal breathing presenting with class II and III skeletal patterns, also noted that most of the airway measurement has not been affected based on malocclusion.

Upper airway dimensions assessed on lateral cephalometry did not show significant changes in growing children, suggesting that the airway dimensions are mainly established in early childhood and remain mostly stable. ${ }^{25}$ Furthermore, modifications regarding the angle of inclination of the anterior cranial base and the bony nasopharyngeal depth has been reported to have significant influences on breathing in patients with OSA. Indeed, a more obtuse cranial base flexure angle seems to lead the posterior pharyngeal wall attachment more posteriorly, thus improving the airway diameters. ${ }^{21}$ Our OSA sample also showed a less obtuse cranial base flexure angle, particularly in class II malocclusions, and a reduced total lower sagittal depth of the bony nasopharynx. Although no relationship was evident between upper airway variables and AHI severity, it is possible to suppose that this skeletal condition could be an additional risk to the development of OSA.

\section{Limitations}

In the statistical analysis the significance level was set at 0.05 . However, if the value of $P$ was corrected for multiple comparisons, it could be argued that considering the number of multiple $t$ tests, the discerning value of $P$ should have been set at $P=0.0017$; then none of the differences would be likely statistically significant.

The radiographs were obtained while patients were awake and in an upright position for assessing craniofacial and upper airway morphology. However, it is uncertain whether the orientation difference has a negligible effect on children with sleep-disordered breathing and whether the upper airway measurements are affected by the state of consciousness. ${ }^{6,26}$

Another limitation is that direct visualization by a physician still remains the gold standard for airway assessment and lateral cephalometry has poor sensitivity but high specificity. ${ }^{27}$ However, two-dimensional radiographic evaluation can still be considered a reasonable screening tool to be supported with appropriate follow-up. ${ }^{28}$

As explained previously, a negative PSQ was considered a proxy for a negative nPSG. The use of an AHI of 5 events/h as cutoff point can be challenged, because there is no universal consensus.

Furthermore, sexual dimorphism and genetic and environmental factors were not considered in our analyses.

Finally, the evaluation of naso-oropharyngeal upper airway features on lateral cephalometric does not imply improvement in nocturnal breathing function.

\section{CONCLUSION}

The OSA sample showed some distinct craniofacial features compared to a nonlikely OSA group. These differences were not consistently located when sagittal malocclusion was considered.

\section{REFERENCES}

1. Carroll JL. Obstructive sleep-disordered breathing in children: new controversies, new directions. Clin Chest Med. 2003;24(2):261-282.

2. Bixler EO, Vgontzas AN, Lin HM, et al. Sleep disordered breathing in children in a general population sample: prevalence and risk factors. Sleep. 2009;32(6):731-736.

3. Dempsey JA, Veasey SC, Morgan BJ, O'Donnell CP. Pathophysiology of sleep apnea. Physiol Rev. 2010;90(1):47-112.

4. Marcus CL. Pathophysiology of childhood obstructive sleep apnea: current concepts. Respir Physiol. 2000;119(2-3):143-154.

5. Korayem MM, Witmans M, MacLean J, et al. Craniofacial morphology in pediatric patients with persistent obstructive sleep apnea with or without positive airway pressure therapy: a crosssectional cephalometric comparison with controls. Am J Orthod Dentfacial Orthop. 2013;144(1):78-85.

6. Katyal V, Pamula Y, Martin AJ, Daynes CN, Kennedy JD, Sampson WJ. Craniofacial and upper airway morphology in pediatric sleepdisordered breathing: systematic review and meta-analysis. Am J Orthod Dentofacial Orthop. 2013;143(1):20-30. 
Huynh NT, Morton PD, Rompré PH, Papadakis A, Remise C. Associations between sleep-disordered breathing symptoms and facial and dental morphometry, assessed with screening examinations. Am J Orthod Dentofacial Orthop. 2011;140(6):762-770.

8. Juliano ML, Machado MA, de Carvalho LB, et al. Polysomnographic Findings are associated with cephalometric measurements in mouthbreathing children. J Clin Sleep Med. 2009;5(6):554-561.

Chervin RD, Weatherly RA, Garetz S, et al. Pediatric sleep questionnaire: prediction of sleep apnea and outcomes. Arch Otolaryngol Head Neck Surg. 2007;133(3):216-222.

10.

Flores-Mir C, Korayem M, Heo G, Witmans M, Major MP, Major PW. Craniofacial morphological characteristics in children with obstructive sleep apnea syndrome: a systematic review and metaanalysis. J Am Dent Assoc. 2013;144(3):269-277.

11. Buyuk SK, Genc E, Simsek H, Karaman A. Analysis of facial soft tissue values and cranial skeletal widths in different body mass index percentile adolescent subjects. Cranio. 2019;37(4):223-230.

12. Villa MP, Pietropaoli N, Supino MC, et al. Diagnosis of pediatric obstructive sleep apnea syndrome in setting with limited resources. JAMA Otolaryngol Head Neck Surg. 2015;141(11):990-996.

13. Martin O, Muelas L, Viñas MJ. Nasopharyngeal cephalometric study of ideal occlusions. Am $J$ Orthod Dentofacial Orthop. 2006;130(4):436.e1-9.

14. Chang SJ, Chae KY. Obstructive sleep apnea syndrome in children: Epidemiology, pathophysiology, diagnosis and sequelae. Korean $J$ Pediatr. 2010;53(10):863-871.

15. Miles PG, Vig PS, Weyant RJ, Forrest TD, Rockette HE Jr. Craniofacial structure and obstructive sleep apnea syndrome: a qualitative analysis and meta-analysis of the literature. Am J Orthod Dentofacial Orthop. 1996;109(2):163-172.

16. Zucconi M, Caprioglio A, Calori G, et al. Craniofacial modifications in children with habitual snoring and obstructive sleep apnoea: a casecontrol study. Eur Respir J. 1999;13(2):411-417.

17. de Freitas MR, Alcazar NMPV, Janson G, de Freitas KM, Henriques JF. Upper and lower pharyngeal airways in subjects with Class I and Class II malocclusions and different growth patterns. Am J Orthod Dentofacial Orthop. 2006;130(6):742-745.

18. Hoekema A, Hovinga B, Stegenga B, De Bont LGM. Craniofacial morphology and obstructive sleep apnoea: a cephalometric analysis. J Oral Rehabil. 2003;30(7):690-696.

19. Zettergren-Wijk L, Forsberg CM, Linder-Aronson S. Changes in dentofacial morphology after adeno-tonsillectomy in young children with obstructive sleep apnoea--a 5-year follow-up study. Eur $J$ Orthod. 2006; 28(4):319-326.

20. Steinberg B, Fraser B. The cranial base in obstructive sleep apnea. $J$ Oral Maxillofac Surg. 1995;53(10):1150-1154.

21. Özdemir H, Altin R, Sögüt A, et al. Craniofacial differences according to AHI scores of children with obstructive sleep apnoea syndrome: cephalometric study in 39 patients. Pediatr Radiol. 2004;34(5):393399.
22. Vig KW. Nasal obstruction and facial growth: the strength of evidence for clinical assumptions. Am J Orthod Dentofacial Orthop. 1998;113(6):603-611.

23. Hoekema A, Hovinga B, Stegenga B, De Bont LGM. Craniofacial morphology and obstructive sleep apnoea: a cephalometric analysis. J Oral Rehabil. 2003;30(7):690-696.

24. Alves Milanezi PV, Zhao L, O’Gara M, Patel PK, Bolognese AM. Three-dimensional cephalometric study of upper airway space in skeletal Class II and III healthy patients. J Craniofac Surg. 2008;19(6):1497-1507. Siche?

25. Mislik B, Hänggi MP, Signorelli L, Peltomäki TA, Patcas R. Pharyngeal airway dimensions: a cephalometric, growth-study based analysis of physiological variations in children aged 6-17. Eur J Orthod. 2014;36(3):331-339.

26. Pracharktam N, Hans MG, Strohl KP, Redline S. Upright and supine cephalometric evaluation of obstructive sleep apnea syndrome and snoring subjects. Angle Orthod. 1994;64(1):63-73.

27. Major MP, Flores-Mir C, Major PW. Assessment of lateral cephalometric diagnosis of adenoid hypertrophy and posterior upper airway obstruction: A systematic review. Am J Orthod Dentofacial Orthop. 2006;130(6):700-708.

28. Eslami E, Katz ES, Baghdady M, Abramovitch K, Masoud MI. Are three-dimensional airway evaluations obtained through computed and cone-beam computed tomography scans predictable from lateral cephalograms? A systematic review of evidence. Angle Orthod. 2017;87(1):159-167.

\section{SUBMISSION \& CORRESPONDENCE INFORMATION}

\section{Submitted for publication February 11, 2019 Submitted in final revised form April 17, 2019 Accepted for publication May 18, 2019}

Address correspondence to: Letizia Perillo, DDS, MS, $\mathrm{PhD}$, Orthodontic Program, Multidisciplinary Department of Medical-Surgical and Dental Specialties, University of Campania Luigi Vanvitelli Via Luigi De Crecchio 6, 80138 Napoli, Italy; Email: letizia.perillo@unicampania.it; letizia.perillo@gmail.com; Phone: +390815665495 / 5501

\section{DISCLOSURE STATEMENT}

The authors have no conflicts of interest to disclose. 
Appendix I. Definitions of the cephalometric linear and angular measurements.

\begin{tabular}{|c|c|}
\hline \multicolumn{2}{|c|}{ Cephalometric measurements } \\
\hline $\mathbf{S}-\mathbf{N}(\mathbf{m m})$ & Distance between Sella and Nasion: length of anterior cranial base \\
\hline ANS-PNS (mm) & Distance between Anterior Nasal Spine and Posterior Nasal Spine: length of palate \\
\hline Go-Me (mm) & Distance between Gonion and Menton: length of mandibular body \\
\hline SNA $\left({ }^{\circ}\right)$ & Angle between Sella-Nasion-A point: maxillary antero-posterior projection \\
\hline SNB $\left({ }^{\circ}\right)$ & Angle between Sella-Nasion-B point: mandibular antero-posterior projection \\
\hline ANB $\left({ }^{\circ}\right)$ & Angle between A point-Nasion - B point: relative position of mandible to maxilla \\
\hline Wits (mm) & Distance between perpendicular lines to occlusal plane at A and B points \\
\hline A-NPerp (mm) & A point perpendicular line to Frankfort horizontal at N: maxillary projection \\
\hline B-NPerp (mm) & B point perpendicular line to Frankfort horizontal at N: mandibular projection \\
\hline U1-PP $\left(^{\circ}\right)$ & $\begin{array}{l}\text { Angle of long axis of upper incisor and palatal plane: angulation of maxillary incisor to } \\
\text { palatal plane }\end{array}$ \\
\hline IMPA $\left(^{\circ}\right)$ & $\begin{array}{l}\text { Angle of long axis of lower incisor and mandibular plane: angulation of mandibular } \\
\text { incisor to mandibular plane }\end{array}$ \\
\hline SN^PHF $\left({ }^{\circ}\right)$ & Angle between anterior cranial base and Frankfort plane \\
\hline FMA $\left(^{\circ}\right)$ & Angle between mandibular plane and Frankfort plane \\
\hline PP-SN $\left({ }^{\circ}\right)$ & $\begin{array}{l}\text { Angle of palatal plane and SN plane: vertical inclination of palate relative to cranial } \\
\text { base }\end{array}$ \\
\hline PP-Go-Me $\left(^{\circ}\right)$ & Angle between palatal plane and mandibular plane: intermaxillar angle \\
\hline SN-GoMe $\left(^{\circ}\right)$ & Angle between SN plane and mandibular plane \\
\hline S-Go/N (Me (ratio) & $\begin{array}{l}\text { Distance between S and Gonion / distance between Nasion and Menton: total posterior } \\
\text { facial height /total anterior facial height }\end{array}$ \\
\hline $\begin{array}{l}\text { Ar-Go/ANS-Me } \\
\text { (ratio) }\end{array}$ & $\begin{array}{l}\text { Distance between Articulare and Gonion / distance between Anterior Nasal Spine and } \\
\text { Menton: lower posterior facial height / lower anterior facial height }\end{array}$ \\
\hline $\operatorname{ArGoMe~}\left(^{\circ}\right)$ & The angle of a line connecting Articulare and mandibular plane: angle of mandible \\
\hline
\end{tabular}

Alves Milanezi PV, Zhao L, O'Gara M, Patel PK, Bolognese AM. Three-dimensional cephalometric study of upper airway space in skeletal Class II and III healthy patients. J Craniofac Surg. 2008;19(6):1497-1507. 
Appendix II. Definitions of the cephalometric measurements of the upper airways.

PNS-AD1

AD1-Ba

PNS-AD2

AD2-H

PNS-Ba

PNS-H

McNamara's upper pharynx dimension

McNamara's lower pharynx dimension
Distance between the closest adenoid tissue and posterior nasal spine measured through the PNS-Ba line (AD1): lower airway thickness

Soft-tissue width at the posterior nasopharynx wall through the posterior nasal spine-Basion line: lower adenoid thickness

Distance between the closest adenoid tissue and the posterior nasal spine and measured through a perpendicular line to Sella-Basion from the posterior nasal spine (AD2): upper airway thickness

Soft-tissue width at the posterior nasopharynx wall through the posterior nasal spine-Hormion line $(\mathrm{H}$, Hormion, point located at the intersection between the perpendicular line to Sella - Basion from posterior nasal spine and the cranial base): upper adenoid thickness

Distance between the posterior nasal spine and the Basion: total lower sagittal depth of the bony nasopharynx

Distance between the posterior nasal spine and the Hormion point: total upper airway thickness

Distance between closest point on the posterior pharynx wall and the upper soft palate

Distance between the point where the posterior tongue contour crosses the mandible and the closest point on the posterior pharynx wall and the point where the posterior tongue contour intersects the mandible 
Appendix III. Comparison between $\mathrm{AHI}>5 / \mathrm{AHI}<5$ and skeletal and upper airway variables.

\begin{tabular}{|c|c|c|c|}
\hline Variables & $\begin{array}{c}\text { AHI }>5 \\
N=13\end{array}$ & $\begin{array}{c}\mathbf{A H I}<5 \\
\mathbf{N}=9\end{array}$ & $P$-value \\
\hline \multicolumn{4}{|l|}{ Skeletal } \\
\hline Age & $9.34 \pm 2.17$ & $8.20 \pm 0.83$ & 0.15 \\
\hline $\mathrm{S}-\mathrm{N}$ & $62.38 \pm 2.75$ & $61.89 \pm 3.75$ & 0.72 \\
\hline ANS-PNS & $42.85 \pm 3.93$ & $41.67 \pm 1.80$ & 0.41 \\
\hline Go-Me & $61.88 \pm 4.53$ & $57.22 \pm 4.60$ & 0.029 \\
\hline SNA & $79.50 \pm 4.11$ & $80.77 \pm 1.92$ & 0.39 \\
\hline SNB & $76.31 \pm 4.34$ & $75.89 \pm 3.69$ & 0.81 \\
\hline ANB & $3.19 \pm 2.95$ & $4.88 \pm 2.26$ & 0.16 \\
\hline WITS & $-0.58 \pm 4.57$ & $1.78 \pm 3.96$ & 0.22 \\
\hline A-NPerp & $0.76 \pm 3.05$ & $0.83 \pm 2.23$ & 0.95 \\
\hline B-NPerp & $-3.96 \pm 6.51$ & $-4.66 \pm 5.02$ & 0.78 \\
\hline $\mathrm{SN}^{\wedge} \mathrm{PHF}$ & $10.92 \pm 2.66$ & $10.22 \pm 1.56$ & 0.48 \\
\hline FMA & $23.46 \pm 4.50$ & $22.89 \pm 4.57$ & 0.77 \\
\hline $\mathrm{SN}^{\wedge} \mathrm{GoMe}$ & $34.38 \pm 4.50$ & $33.00 \pm 4.18$ & 0.47 \\
\hline $\mathrm{PP}^{\wedge} \mathrm{SN}$ & $7.62 \pm 2.39$ & $7.44 \pm 1.50$ & 0.85 \\
\hline $\mathrm{PP}^{\wedge} \mathrm{GoMe}$ & $26.77 \pm 4.49$ & $25.56 \pm 5.34$ & 0.57 \\
\hline $\mathrm{ArGo}^{\wedge} \mathrm{Me}$ & $125.0 \pm 4.76$ & $127.00 \pm 6.36$ & 0.40 \\
\hline $\mathrm{Ba}^{\wedge} \mathrm{SN}$ & $131.31 \pm 3.98$ & $127.33 \pm 3.50$ & 0.026 \\
\hline S-Go/N-Me & $61.85 \pm 4.48$ & $64.89 \pm 3.48$ & 0.10 \\
\hline Ar-Go/Ans-Me & $68.80 \pm 7.26$ & $74.55 \pm 6.46$ & 0.07 \\
\hline \multicolumn{4}{|l|}{ Dental } \\
\hline U1-PP & $113.00 \pm 6.94$ & $117.78 \pm 6.18$ & 0.11 \\
\hline IMPA & $92.38 \pm 6.52$ & $94.44 \pm 4.97$ & 0.42 \\
\hline \multicolumn{4}{|l|}{ Upper Airway } \\
\hline PNS-AD1 & $18.62 \pm 5.81$ & $17.89 \pm 4.45$ & 0.75 \\
\hline AD1-Ba & $21.77 \pm 4.12$ & $22.22 \pm 3.38$ & 0.78 \\
\hline PNS-Ba & $40.46 \pm 2.78$ & $40.11 \pm 3.01$ & 0.78 \\
\hline PNS-AD2 & $12.19 \pm 3.60$ & $12.11 \pm 2.02$ & 0.95 \\
\hline $\mathrm{AD} 2 \mathrm{H}$ & $16.69 \pm 4.00$ & $18.44 \pm 2.78$ & 0.27 \\
\hline PNS-H & $28.88 \pm 2.80$ & $30.33 \pm 2.95$ & 0.25 \\
\hline McNamara upper pharynx & $10.46 \pm 2.29$ & $9.11 \pm 3.06$ & 0.25 \\
\hline McNamara middle pharynx & $9.69 \pm 2.59$ & $9.11 \pm 1.76$ & 0.56 \\
\hline McNamara lower pharynx & $10.23 \pm 2.45$ & $8.56 \pm 2.35$ & 0.12 \\
\hline
\end{tabular}


Appendix IV. Comparison between $\mathrm{AHI}>5 /<5$ and cephalometrics in OSA Class II.

\begin{tabular}{|c|c|c|c|}
\hline Variables & $\begin{array}{c}\text { AHI>5 } \\
N=5\end{array}$ & $\begin{array}{c}\mathbf{A H I}<5 \\
N=6\end{array}$ & $P$-value \\
\hline \multicolumn{4}{|l|}{ Skeletal } \\
\hline Age & $9.30 \pm 2.92$ & $7.95 \pm 0.52$ & 0.29 \\
\hline $\mathrm{S}-\mathrm{N}$ & $64.00 \pm 2.12$ & $61.00 \pm 3.94$ & 0.16 \\
\hline ANS-PNS & $45.20 \pm 2.58$ & $41.66 \pm 2.16$ & 0.03 \\
\hline Go-Me & $61.80 \pm 4.81$ & $56.66 \pm 5.71$ & 0.14 \\
\hline SNA & $80.60 \pm 4.56$ & $80.00 \pm 1.67$ & 0.77 \\
\hline SNB & $74.60 \pm 4.87$ & $74.00 \pm 2.60$ & 0.80 \\
\hline ANB & $6.00 \pm 2.44$ & $6.00 \pm 1.09$ & 1.00 \\
\hline WITS & $3.80 \pm 3.11$ & $4.00 \pm 2.52$ & 0.90 \\
\hline A-NPerp & $1.20 \pm 3.70$ & $0.16 \pm 2.40$ & 0.58 \\
\hline B-NPerp & $-8.00 \pm 6.16$ & $-7.16 \pm 4.11$ & 0.79 \\
\hline $\mathrm{SN}^{\wedge} \mathrm{PHF}$ & $10.40 \pm 0.54$ & $10.00 \pm 1.78$ & 0.64 \\
\hline FMA & $26.00 \pm 5.74$ & $23.00 \pm 5.47$ & 0.39 \\
\hline $\mathrm{SN}^{\wedge} \mathrm{GoMe}$ & $36.40 \pm 5.85$ & $32.83 \pm 4.87$ & 0.29 \\
\hline $\mathrm{PP}^{\wedge} \mathrm{SN}$ & $7.20 \pm 1.92$ & $7.16 \pm 1.72$ & 0.97 \\
\hline $\mathrm{PP}^{\wedge} \mathrm{GoMe}$ & $29.20 \pm 6.14$ & $25.66 \pm 6.21$ & 0.37 \\
\hline $\mathrm{ArGo}^{\wedge} \mathrm{Me}$ & $125.60 \pm 3.78$ & $125.50 \pm 7.00$ & 0.97 \\
\hline $\mathrm{Ba}^{\wedge} \mathrm{SN}$ & $131.00 \pm 2.54$ & $128.66 \pm 2.25$ & 0.14 \\
\hline S-Go/N-Me & $60.60 \pm 6.58$ & $65.33 \pm 3.50$ & 0.16 \\
\hline Ar-Go/Ans-Me & $64.40 \pm 8.38$ & $72.83 \pm 6.73$ & 0.09 \\
\hline \multicolumn{4}{|l|}{ Dental } \\
\hline U1-PP & $113.80 \pm 3.11$ & $116.33 \pm 6.59$ & 0.45 \\
\hline IMPA & $96.20 \pm 4.96$ & $96.16 \pm 3.43$ & 0.90 \\
\hline \multicolumn{4}{|l|}{ Upper Airway } \\
\hline PNS-AD1 & $20.80 \pm 5.58$ & $17.66 \pm 4.41$ & 0.32 \\
\hline AD1-Ba & $20.80 \pm 4.14$ & $21.66 \pm 3.82$ & 0.72 \\
\hline PNS-Ba & $41.60 \pm 3.71$ & $39.33 \pm 1.96$ & 0.22 \\
\hline PNS-AD2 & $13.20 \pm 4.76$ & $11.83 \pm 1.72$ & 0.52 \\
\hline $\mathrm{AD} 2 \mathrm{H}$ & $15.20 \pm 4.54$ & $17.66 \pm 2.94$ & 0.30 \\
\hline PNS-H & $28.40 \pm 4.03$ & $29.16 \pm 2.04$ & 0.69 \\
\hline McNamara upper pharynx & $10.60 \pm 2.19$ & $8.16 \pm 2.99$ & 0.16 \\
\hline McNamara middle pharynx & $10.00 \pm 2.23$ & $9.83 \pm 1.72$ & 0.89 \\
\hline McNamara lower pharynx & $11.40 \pm 2.19$ & $9.00 \pm 2.75$ & 0.15 \\
\hline
\end{tabular}


Appendix V. Comparison between $\mathrm{AHI}>5 /<5$ and cephalometrics in OSA Class III.

\begin{tabular}{|c|c|c|c|}
\hline Variables & $\begin{array}{c}\mathbf{A H I}>5 \\
\mathbf{N}=8\end{array}$ & $\begin{array}{c}\mathbf{A H I}<5 \\
\mathbf{N}=3\end{array}$ & $P$-value \\
\hline \multicolumn{4}{|l|}{ Skeletal } \\
\hline Age & $9.37 \pm 1.80$ & $8.70 \pm 1.24$ & 0.57 \\
\hline $\mathrm{S}-\mathrm{N}$ & $61.37 \pm 2.72$ & $63.66 \pm 3.21$ & 0.26 \\
\hline ANS-PNS & $41.37 \pm 4.03$ & $41.66 \pm 1.15$ & 0.90 \\
\hline Go-Me & $61.93 \pm 4.69$ & $58.33 \pm 0.57$ & 0.23 \\
\hline SNA & $78.81 \pm 3.96$ & $82.33 \pm 1.52$ & 0.17 \\
\hline SNB & $77.37 \pm 3.92$ & $79.76 \pm 2.30$ & 0.37 \\
\hline ANB & $1.43 \pm 1.54$ & $2.66 \pm 2.51$ & 0.34 \\
\hline WITS & $-3-31 \pm 2.84$ & $-2.66 \pm 1.52$ & 0.72 \\
\hline A-NPerp & $0.50 \pm 2.82$ & $2.16 \pm 1.25$ & 0.36 \\
\hline B-NPerp & $-1.43 \pm 5.66$ & $-0.33 \pm 1.52$ & 0.61 \\
\hline $\mathrm{SN}^{\wedge} \mathrm{PHF}$ & $11.25 \pm 3.41$ & $10.66 \pm 1.15$ & 0.78 \\
\hline FMA & $21.87 \pm 2.90$ & $22.66 \pm 2.08$ & 0.68 \\
\hline $\mathrm{SN}^{\wedge} \mathrm{GoMe}$ & $33.12 \pm 3.22$ & $33.33 \pm 3.21$ & 0.92 \\
\hline $\mathrm{PP}^{\wedge} \mathrm{SN}$ & $7.87 \pm 2.74$ & $8.00 \pm 1.00$ & 0.94 \\
\hline $\mathrm{PP}^{\wedge} \mathrm{GoMe}$ & $25.25 \pm 2.49$ & $25.33 \pm 4.16$ & 0.96 \\
\hline $\mathrm{ArGo}^{\wedge} \mathrm{Me}$ & $124.62 \pm 5.50$ & $130.00 \pm 4.35$ & 0.16 \\
\hline $\mathrm{Ba}^{\wedge} \mathrm{SN}$ & $131.50 \pm 4.84$ & $124.66 \pm 4.50$ & 0.06 \\
\hline S-Go/N-Me & $62.62 \pm 2.82$ & $64.00 \pm 4.00$ & 0.53 \\
\hline Ar-Go/Ans-Me & $71.56 \pm 5.26$ & $78.00 \pm 5.19$ & 0.10 \\
\hline \multicolumn{4}{|l|}{ Dental } \\
\hline U1-PP & $112.50 \pm 8.73$ & $120.66 \pm 5.03$ & 0.16 \\
\hline IMPA & $90.00 \pm 6.00$ & $91.00 \pm 6.55$ & 0.81 \\
\hline \multicolumn{4}{|l|}{ Upper Airway } \\
\hline PNS-AD1 & $17.25 \pm 5.87$ & $18.33 \pm 5.50$ & 0.78 \\
\hline $\mathrm{AD} 1-\mathrm{Ba}$ & $22.37 \pm 4.27$ & $23.33 \pm 2.51$ & 0.72 \\
\hline PNS-Ba & $39.75 \pm 1.98$ & $41.66 \pm 4.61$ & 0.33 \\
\hline PNS-AD2 & $11.56 \pm 2.84$ & $12.66 \pm 2.88$ & 0.58 \\
\hline $\mathrm{AD} 2 \mathrm{H}$ & $17.62 \pm 3.62$ & $20.00 \pm 2.00$ & 0.32 \\
\hline PNS-H & $29.18 \pm 1.96$ & $32.66 \pm 3.51$ & 0.06 \\
\hline McNamara upper pharynx & $10.37 \pm 2.50$ & $11.00 \pm 2.64$ & 0.72 \\
\hline McNamara middle pharynx & $9.50 \pm 2.92$ & $7.66 \pm 0.57$ & 0.32 \\
\hline McNamara lower pharynx & $9.50 \pm 2.44$ & $7.66 \pm 1.15$ & 0.25 \\
\hline
\end{tabular}


Appendix VI. Correlation among OSA variables and AHI Index.

\begin{tabular}{|c|c|c|}
\hline \multirow[b]{2}{*}{ Variables } & \multicolumn{2}{|c|}{ AHI index } \\
\hline & $r$ & $P$-value \\
\hline Age & 0.38 & 0.04 \\
\hline $\mathrm{S}-\mathrm{N}$ & 0.01 & 0.95 \\
\hline ANS-PNS & -0.12 & 0.58 \\
\hline Go-Me & 0.08 & 0.71 \\
\hline SNA & -0.06 & 0.77 \\
\hline SNB & -0.23 & 0.30 \\
\hline ANB & -0.33 & 0.12 \\
\hline WITS & -0.10 & 0.64 \\
\hline A-Nperp & -0.11 & 0.62 \\
\hline B-Nperp & 0.027 & 0.90 \\
\hline U1-PP & -0.24 & 0.91 \\
\hline IMPA & -0.11 & 0.61 \\
\hline $\mathrm{SN}^{\wedge} \mathrm{PHF}$ & -0.24 & 0.26 \\
\hline FMA & -0.11 & 0.61 \\
\hline $\mathrm{SN}^{\wedge} \mathrm{GoMe}$ & -0.23 & 0.28 \\
\hline $\mathrm{PP}^{\wedge} \mathrm{SN}$ & -0.24 & 0.26 \\
\hline $\mathrm{PP}^{\wedge} \mathrm{GoMe}$ & -0.10 & 0.62 \\
\hline $\mathrm{ArGo}^{\wedge} \mathrm{Me}$ & -0.11 & 0.60 \\
\hline $\mathrm{Ba}^{\wedge} \mathrm{SN}$ & 0.15 & 0.49 \\
\hline S-Go/N-Me & 0.06 & 0.77 \\
\hline Ar-Go/Ans-Me & 0.09 & 0.67 \\
\hline PNS-AD1 & -0.18 & 0.93 \\
\hline AD1-Ba & 0.15 & 0.49 \\
\hline PNS-Ba & 0.17 & 0.44 \\
\hline PNS-AD2 & 0.11 & 0.61 \\
\hline $\mathrm{AD} 2 \mathrm{H}$ & 0.00 & 1.0 \\
\hline PNS-H & 0.14 & 0.53 \\
\hline McNam up pharynx & -0.49 & 0.83 \\
\hline McNam mid pharynx & -0.13 & 0.56 \\
\hline McNam low pharynx & 0.06 & 0.75 \\
\hline
\end{tabular}

